\title{
Carpal tunnel syndrome: The role of occupational factors
}

\author{
Professor Keith T Palmer, MA DM FFRCP FFOM [Professor of Occupational Medicine] \\ [MRC Clinical Scientist] [Consultant Occupational Physician] \\ MRC Epidemiology Resource Centre, University of Southampton, UK
}

\begin{abstract}
Carpal Tunnel Syndrome is a fairly common condition in working-aged people, sometimes caused by physical occupational activities, such as repeated and forceful movements of the hand and wrist or use of hand-held powered vibratory tools. Symptoms may be prevented or alleviated by primary control measures at work and some cases of disease are compensable. Following a general description of the disorder, its epidemiology, and some of the difficulties surrounding diagnosis, this review focuses on the role of occupational factors in causation of CTS and factors that can mitigate risk. Areas of uncertainty, debate and research interest are emphasised where relevant.
\end{abstract}

\section{Introduction}

Carpal Tunnel Syndrome (CTS) is a peripheral mono-neuropathy of the upper limb, caused by compression of the median nerve as it passes through the carpal tunnel into the wrist. In the carpal tunnel the median nerve lies immediately beneath the palmaris longus tendon and anterior to the flexor tendons. Conditions which decrease the tunnel's size, or swell the structures contained within it, compress the median nerve against the transverse ligament bounding the tunnel's roof. Such circumstances can arise traumatically, congenitally, or due to systemic or inflammatory effects. Known causes of CTS include diabetes mellitus, rheumatoid arthritis, acromegaly, hypothyroidism, pregnancy and tenosynovitis [1]. This review focuses, however, on putative occupational causes. Following a general description of CTS, its epidemiology in the working age population, its presenting clinical features and investigation, attention is given to well-established and suspected risk factors in the workplace, and the compensation, prevention and optimum management of work-associated cases.

\section{Clinical features}

\begin{abstract}
Classically, the syndrome of CTS comprises sensory and motor features in the median nerve distribution of the hand, together with evidence of delayed nerve conduction. The history is of gradual onset of numbness and tingling in the median nerve distribution of the hand. Pain is also reported. Strenuous use of the hand tends to aggravate symptoms, although this may not become apparent until several hours after activity. Night time pain disturbs sleep, and patients often hang the affected hand over the side of the bed to gain relief. Many sufferers complain of progressive weakness and clumsiness in their hands. Tinel's test (percussion over the flexor retinaculum) and Phalen's test (sustained complete flexion of the wrist for a minute or so) may provoke parasthesiae over a median nerve distribution.
\end{abstract}

Compression of the nerve results in damage to the myelin sheath and manifests as delayed latencies and slowed conduction velocities: electrodiagnosis rests upon demonstrating

Correspondence to: Prof Keith Palmer, MRC Epidemiology Resource Centre, Southampton General Hospital, Tremona Road, Southampton, SO16 6YD, UK, Telephone: +44 (0) 238077 7624, Fax: +44 (0) 238070 4021, ktp@ mrc.soton.ac.uk. 
impaired median nerve conduction across the carpal tunnel in context of normal conduction elsewhere.

\section{Case definitions and diagnosis}

Nerve conduction, with its objectivity and relationship to mechanism, is treated as a reference standard. However, diagnosis is less simple in clinical experience (and especially in surveys of general and working populations) than implied by the foregoing description. Sensory symptoms are common in the absence of obvious pathology ( $>30 \%$ of adults in one British population survey reported sensory symptoms in the digits in the past 7 days [2]); patients may forget the distribution of their symptoms; and questions arise as to the interpretation of compatible but non-classical presentations (e.g. whether symptoms confined to only one of the three median digits is indicative of CTS). 'Classical' symptoms, and improvement with surgery, occur despite normal nerve conduction; delayed nerve conduction occurs fairly often in asymptomatic individuals; and Tinel's and Phalen's signs can be found in the absence of other syndromic features [1]. Thus, the relation between elements of the triad (symptoms, signs, and nerve conduction) is inconstant, making for a reference standard that is imperfect.

The ensuing uncertainty contributes to variation in practice, with physicians entertaining differing views about essential diagnostic features. Thus, when Graham et al (2006) asked 99 physicians and surgeons to score 57 potential criteria on a visual analogue scale, they found remarkably little agreement beyond chance within and between specialties [3].

In research, the situation - though far from ideal - is rather better. The hand diagrams of Katz et al [4] represent a standardised, widely used method of collecting patients' symptom histories. By pre-specifying and agreeing the shading patterns of 'classical', 'probable' and 'possible' distributions of CTS-like symptoms, different observers have reached acceptable agreement over case history. In one workplace study two observers achieved a 96\% agreement over the rating of 255 hand diagrams collected from workers at 12 worksites [5]; and in another, good agreement was found between three experienced clinicians assessing the hand diagrams of 333 employees [6]. Others, by pre-specifying a combination of symptoms and signs, have shown that research-trained observers can agree reasonably well [7].

Reproducibility of case history is a useful achievement, although not synonymous with validity of diagnosis. (By analogy, badly calibrated weighing scales can offer repeatable but erroneous data.) Nor has disagreement in research been eliminated entirely; rather it is manifest in debate about interpretation of the hand diagram. Katz and Stirrat [4] have defined symptoms of CTS as "classical" if they affect at least two of digits 1-3 but not the palm or dorsum of the hand, as "probable" if the palm is also involved, and as "possible" if symptoms are reported in only one of digits $1-3$. Minor modifications to these criteria have been suggested by Franzblau et al [8] and Rempel et al [9].

The Katz hand diagram (and other features like Tinel's and Phalen's signs) have been assessed for their positive and negative likelihood ratios (LRs), assuming that nerve conduction is a sufficient, if imperfect reference standard (Table 1) [5,10,11]. LRs assess how much a positive diagnostic test raises (or a negative test lowers) the post-probability of disease, and so offer an appealing framework for judging a test's influence on clinical decision-making - the higher the +LR the better a test will be at ruling in a disease, the lower the -LR the better at ruling out a disease. However, by the criteria of Jaeschke et al 1994 [12], the LRs in Table 1 do not suggest a 'significant' shift in the post-test likelihood. 
The failure may be one of case mix among the generally milder cases found in workplace and the community. Thus, a 'classical' distribution of (Katz definition) is reported to be sensitive and specific for delayed median nerve conduction in patients under hospital investigation [4]; but the criteria have not predicted delayed nerve conduction in community [8] or occupational [9] samples. A community survey by Ferry et al. [13] also explored the relation of delayed nerve conduction to various other symptom patterns, including hand symptoms that excluded the fifth digit, the dorsum, or both of these sites, but found the correlation to be similarly poor.

The want of an ideal reference standard, especially beyond the hospital confines, has knock on effects for the descriptive epidemiology of CTS and for research aimed at prevention and treatment.

\section{Epidemiology}

Estimates of the prevalence and incidence of CTS depend critically on the adopted case definition. The partial concordance of the diagnostic triad (above) allows for several choices, and a range of plausible cut-points exists for defining electrophysiological abnormality. Different choices generate markedly different estimates of prevalence [13].

In a large Dutch population survey that defined CTS as sensory disturbance in the median nerve distribution occurring at least twice a week, generally awakening the patient from sleep, and associated with nerve conduction abnormalities, the point prevalence was $0.6 \%$ in men and $8 \%$ in women [11].

In a British population survey, estimates were made of sensory symptoms in various anatomical distributions (Table 2) [2]. 'Classical' CTS - defined as symptoms extensively affecting the palmar surfaces of the medial three digits and not felt elsewhere - was reported by $1.2 \%$ of adults and 'probable CTS (less extensive symptoms, but still restricted to the median nerve distribution) affected a further $2.2 \%$ of adults. Symptomatic respondents from the same survey were examined for physical signs, and this resulted in an estimated population prevalence of $0.9 \%$, rising somewhat with age [14]. Table 2 shows that other patterns of sensory involvement in the digits are very common, with 6-7\% of respondents shading all of the digits in one or both of their hands as affected: thus, surveys which define cases on 'soft' definitions of symptom distribution generate markedly higher estimates of prevalence (14-19\% in some investigations $[15,16])$.

Estimates of prevalence and incidence depend on the setting in which inquiries are made. The crude incidence rate is reported to be one per thousand person years in hospitaldiagnosed patients $[17,18]$ and around two per thousand person-years in primary care [19]. In selected working populations, CTS is somewhat more common (1-2\%), using clinicallybased criteria $[20,21]$.

The age-adjusted incidence rate of CTS may be increasing in the general population [17,22], but exact comparisons between surveys are difficult as case definitions have changed over time, following the introduction of electrophysiological testing.

\section{Research-driven case definitions}

Ferry et al have developed an instrument to assess the disability from CTS, which incorporates domains such as sleep disturbance, clumsiness, and difficulty with writing, dressing and driving [15]. The researchers explored case definitions based on symptoms and nerve conduction in the community, and found consistently higher levels of self-reported disability in those with electrophysiological abnormalities. 
This example suggests a research-driven basis for refinement of case definition: 'more correct' definitions (those closer to 'the truth') should display stronger correlations with prognosis, effective treatments, and established causes of disease [23]. This phenomenon arises because the natural gradients between exposure and response are attenuated by diagnostic misclassification; good case definitions involve less misclassification, allowing dose-response effects to shine through. Where stronger associations (risks from exposure or benefits from treatment) are found, two useful conclusions flow - case definition A is more accurate than case definition $\mathrm{B}$, while the magnitude of risk (or benefit) is greater than might be supposed from research with $\mathrm{B}$ as the operational case definition.

Table 3 illustrates the principle. The data derive from a survey of workers manufacturing ski equipment [24], some in jobs with frequent hand-wrist repetition and some in non-repetitive work. Both groups were classified as having CTS by several case definitions. The more specific detailed case definition (delayed nerve conduction with a positive Tinel's or Phalen's test) showed a much stronger association with repetition than non-specific symptoms (e.g. nocturnal hand pain), suggesting both that this definition is a better marker of CTS and that risks of the activity are reasonably high.

Analogously, in the British population survey mentioned above, associations were explored between various symptom patterns and risk factors for sensory hand symptoms (Table 4) [2]. Repetitive work activity was associated only with the extensive median pattern of sensory symptoms (classical CTS-like symptoms), whereas low vitality and painfully restricted neck movements were associated only with non-median symptoms. Studies like these vindicate textbook clinical teaching, and help to define tools for field research, despite ongoing debate about the optimum reference standard.

\section{Classifying occupational exposures}

In evaluating occupational risk factors, problems of misclassification beset estimation of exposures, just as they do the determination of disease outcome. Factors such as the degree of repetition inherent in a job, the pacing of work activities, the work-rest cycle, and the torques acting at the wrist are challenging to measure; in most jobs they are highly variable; representativeness of sampling is an issue, as is the appropriate method of integrating exposures (e.g. how short-term exposures should be weighted relative to cumulative lifetime ones).

Many assessment methods have been advocated, though none has achieved primacy. Some time-consuming expensive techniques have value in research, mainly as a means of validating simpler metrics. In some studies, analysis of work activities has been undertaken using panels of video cameras, and with reflective spots or small lights fixed to workers' clothing, so that movements can be tracked, digitally encoded and analysed by computer; in other studies, workers have worn electronic pendulum potentiometers and flexible lightweight strain gauges, to enable computer reconstruction of postures and movements; static postures and joint angles have been mapped using photographs and goniometers; workload and muscle fatigue have been investigated using surface EMG and needle electrodes; and computer key strokes counted using dedicated software. These methods enable biomechanical measurements of force, posture, frequency, and duration to be compared with known human capability, while comparison across jobs allows those with higher risks to be identified. The OSWAS [25] and RULA [26] methods are alternative, simpler approaches to exposure assessment, although still requiring systematic observation of 'representative' work activities by expert observers.

Large scale field research requires cruder methods, ranging from job title through to selfreported exposures. The scope for measurement error is considerable: in one survey, 
intermittent users of hand-powered tools (a known cause of CTS) over-estimated the time that vibration entered their hands by some 2.5 -fold compared with a time and motion study in which they were observed working [27].

Non-systematic errors in exposure assessment tend to attenuate estimates of exposureresponse, in the same fashion as errors of case classification. The degree of error is usually unknown. However, analyses that classify exposures in broad categories ('highly', 'moderately', 'slightly' exposed) can still demonstrate exposure-response effects, as placing workers in rough rank order and contrasting the extremes of exposure (very high vs. none) is more feasible than assigning a correct numerical estimate of exposure.

In the following section, which summarises current knowledge on workplace risk factors and CTS, the various estimates of risk should be read with the above limitations in mind.

\section{Occupational associations}

A review by Hagberg et al in 1992 identified 15 cross-sectional studies and six case-control studies with reasonably high quality information on occupational associations with CTS [28]. Most investigations analysed risks by job title, finding high prevalence rates and relative risks (RR) in a number of jobs believed to involve repetitive and forceful gripping. A second systematic review in the 1990s, by the US National Institute of Occupational Safety and Health, concluded that there was 'evidence' of positive associations with work that entailed highly repetitive or forceful movements of the hands, and 'strong evidence' in relation to the combination of these exposures, but 'insufficient evidence' that the syndrome was caused by extreme wrist postures [29]. A textbook from the same period [30], while not finding positive evidence on all of the so-called Bradford Hill criteria for causality, concluded that there was 'strong evidence supporting the contribution of work-related factors to the development of CTS'.

Updating these earlier reviews, Palmer et al [31] identified 38 relevant reports. Table 5 shows risks of CTS by job title and Table 6 by activities in the job. The occupations and industries studied ranged widely, but most fell into three broad classes - jobs entailing the use of vibratory tools, assembly work, and food processing and packing.

\section{Exposure to vibration}

Nine reports, mostly related to occupation (Table 5 - quarry/rock drillers $[33,34$,

stonemasons [33], forestry workers [32, 35,36), but also including two case-control studies and one household survey (Table $6[57,59,60]$ ), confirm hand-transmitted vibration as a risk factor for CTS. Exposures to vibratory tools tended to be relatively prolonged and intense. In one study, cases had used rock drills for an average of 10 years [34]; in another, foresters had used chainsaws occupationally for >11 years [32]; and in two further studies of foresters, cumulative exposures exceeded 8 years of continuous tool use [35,36]. A casecontrol study of surgically-treated CTS found a more than doubling of risk from work with hand-held vibratory tools, but with exposure durations defined very broadly (between 1 and 20 years) [60], and a second reported a RR of 3.3 for exposure to power tools or machinery for $>6$ hours/day [57].

\section{Assembly work}

Increased risks were reported in ski assembly workers employed an average of five years in jobs involving 'repeated and/or sustained' flexion, extension, or ulnar or radial deviation of the wrist (Odds Ratio (OR) 4.0) [24]; in automobile assembly workers (OR 2.9) [38]; in electrical assembly workers (OR 11.4) [37]; and in workers assembling small electrical appliances, and motor vehicle and ski accessories (OR 4.5) [40]. 
Excess risks were also reported In food processing and food packing - in poultry workers (OR 2.9) [44]; in food processors (two studies) [43,52],; and in frozen food packers (OR 11.7) [42].

Many of these occupations involve prolonged or repeated flexion and extension of the wrist, and in keeping, assessments of risk by main activity (Table 6) find higher risks with these exposures. Four studies $[53,57,59,60]$ found that repeated flexion and extension of the wrist increased the risk of physician-confirmed CTS. Three studies pointed to wrist flexion or extension for at least half of the working day as carrying a notably high risk. In one study risks were elevated 5-8-fold when the self-reported time spent in activities with the wrist flexed or extended was $\geq 20$ hours/week [53], and in a second the OR for CTS was 2.1 to 2.7 for those estimating that they bent/twisted their wrists for $>3.5$ hours per day vs. 0 hours/day [57]. The most telling evidence on force and repetition comes, however, from a well-known and careful survey by Silverstein et al [21], which videotaped workers from 7 different industries. When repetitive work (hand-wrist flexion and extension) was defined by a cycle time of $<30$ seconds or $>50 \%$ of cycle time involving the same activities, the OR was 2.7 in low force (hand force $<1 \mathrm{~kg}$ ) jobs and 15.5 in high force (hand force $>4 \mathrm{~kg}$ ) jobs highlighting an interaction between force and repetition. A study by Tanaka et al [59] found that risks were increased nearly six-fold in workers bending/twisting the hand or wrist 'many times per hour'. Other studies, by Leclerc et al [40,41] and Roquelaure et al [58] found associations with assembly tasks involving a short elemental cycle time ( $<10$ seconds/ repetition).

Use of the computer keyboard and mouse have also been closely studied, but with far less evidence of elevated risk. A painstaking cohort study of 5,000 Danish professional technicians found an association between incident, self-reported sensory symptoms in the median nerve distribution and use of a right-handed mouse, but no association with use of keyboards, and the overall incidence of symptoms was very low, causing the authors to conclude that "computer use does not pose a severe occupational hazard for developing symptoms of CTS" [51]. Other surveys have also proved generally reassuring $[57,61]$.

The studies mentioned here are not without individual limitations. In particular, almost all collected information about exposures retrospectively, with potential for information bias. Some studies were small and some may not have fully controlled for confounding. Conceivably, a few investigations were prompted by workplace clusters, which would lead to unrepresentatively high estimates of risk. Notwithstanding these problems, the body of evidence as a whole is consistent, and the stronger studies, including those that undertook direct assessments of exposure rather than relying on self-report, point in the same direction [31]. Finally, from a biomechanical viewpoint, the findings are plausible. It can be demonstrated experimentally, in human cadavers and animal models, that extreme flexion and extreme extension of the wrist increase the pressure in the carpal tunnel sufficiently to impair blood perfusion of the median nerve [62,63], so that epidemiological and physiological investigations offer a coherent view of causation.

\section{Compensation and statutory reporting}

In many countries industrial diseases are compensated by state welfare benefit for workers who develop illness because of their occupation. In Britain, for example, provisions have existed to cover occupational accidents since 1897 and occupationally-related diseases since 1906. CTS is potentially compensable in users of vibratory tools; and also in those whose jobs entail repeated palmar flexion and dorsiflexion of the wrist for at least 20 hours per week for at least 12 months in aggregate in the 24 months prior to symptom onset ("repeated" means at least once every 30 seconds) [64]. However, only willing, 
knowledgeable and insured workers (employees rather than the self-employed) can lodge a claim, and benefit is only paid under qualifying conditions of occupation and severity. Altogether, the Department for Works and Pensions confirms only about a few hundred cases per year from these causes, most likely the tip of a morbidity iceberg.

In many countries there is also a legal duty to report a scheduled list of work-related illnesses to health and safety enforcement agencies. In Britain, most of the illnesses which are compensable by the State, including CTS, must be notified to the Health and Safety Executive or to local Environmental Health Officers when they occur in qualifying circumstances of exposure. The onus falls on informed employers to submit a return, and under-reporting is recognised to be a wide-spread and significant problem.

\section{Case management and prevention}

The management of work-associated CTS is similar to that of non-occupational CTS, with the important exception of advice on control of causal or aggravating exposures.

Conservative measures may suffice. Recently updated Cochrane reviews report "significant short-term benefit from oral steroids, splinting, ultrasound, yoga and carpal bone mobilisation" and also from local corticosteroid injections $[65,66]$. Electrophysiological evidence of nerve entrapment is generally sought before proceeding to the ultimate step of surgical release, which is usually effective. Ahead of this, measures to mitigate workplace exposures, temporarily (hand-wrist repetition) or permanently (hand-transmitted vibration), may be appropriate. Preventive measures, based on an assumed mechanical pathogenesis, may include: (i) job rotation or job enlargement, to provide respite from work that requires repetitive monotonous use of the same muscles and tendons; (ii) rest breaks; (iii) task optimisation (e.g. better design of tools and equipment, and a better work lay-out make the task easier to perform); (iv) training, to ensure better working practices; (v) an induction period, to allow new employees to start out at a slower pace; (vi) a rehabilitation programme, to ease affected workers back into work, with redeployment, in recalcitrant and recurrent cases. Box 1 summarises some principles of good ergonomic practice drawn from general principles.

Direct empirical evidence on prevention of CTS is limited, however, with few relevant intervention studies. Assuming a precautionary line, highly repetitive wrist-hand work should be avoided by ergonomic design of tasks and tools, and by appropriate scheduling of work and rest periods. It is also important to avoid prolonged use of hand-held vibratory tools insofar as this is possible.

\section{Summary}

CTS is a reasonably common disorder in people of working age, although its diagnosis is not without elements of difficulty and controversy. The disorder can cause functional handicap and is compensable under some circumstances when occupationally related. Clear associations have been established between CTS and workplace activities involving exposure to hand-transmitted vibration and/or repeated and forceful movements of the hand/ wrist; many occupations are at increased risk. Symptoms may be avoidable if good ergonomic practices are followed, and control of mechanical risk factors in the workplace can aid rehabilitation of the affected worker. In vibration-induced CTS, a change of occupation is often indicated. 


\section{Acknowledgments}

Elements of this review were supported by a grant from the Health and Safety Executive with a remit related to optimising case definitions of upper limb disorders. Clare Harris and Cathy Linaker assisted with the necessary literature searches.

\section{References}

1. Croft, P. Soft tissue rheumatism. In: Silman, AJ.; Hochberg, MC., editors. Epidemiology of the Rheumatic Diseases. Oxford University Press; Oxford: 1993. p. 399-408.

2. Reading I, Walker-Bone K, Palmer KT, Cooper C, Coggon D. Anatomic distribution of sensory symptoms in the hand and their relation to neck pain, psychosocial variables and occupational activities. Am J Epidemiol. 2003; 157:524-530. [PubMed: 12631542]

3. Graham D, Dvali L, Regehr G, Wright JG. Variations in diagnostic criteria for carpal tunnel syndrome among Ontario specialists. Am J Ind Med. 2006; 49:8-13. [PubMed: 16362943]

4. Katz JN, Stirrat CR. A self-administered hand diagram for the diagnosis of carpal tunnel syndrome. J Hand Surg [Am]. 1990; 15:360-3.

5. Bonauto DK, Silverstein BA, Fan ZJ, Smith CK, Wicox DN. Evaluation of a symptom diagram for identifying carpal tunnel syndrome. Occup Med. 2008; 58:561-566.

6. Dale AM, Strickland J, Symanzik J, Franzblau A, Evanoff B. Reliability of hand diagrams for the epidemiologic case definition of carpal tunnel syndrome. J Occup Rehab. 2008; 18:233-248.

7. Walker-Bone K, Byng T, Linaker C, Reading I, Coggon D, Palmer KT, Cooper C. Reliability of the Southampton examination schedule for the diagnosis of upper limb disorders in the general population. Ann Rheum Dis. 2002; 61:1103-1106. [PubMed: 12429544]

8. Franzblau A, Werner RA, Albers JW, et al. Workplace surveillance for carpal tunnel syndrome using hand diagrams. J Occup Rehab. 1994; 4:185-98.

9. Rempel D, Evanoff B, Amadio PC, et al. Consensus criteria for the classification of carpal tunnel syndrome in epidemiologic studies. Am J Public Health. 1998; 88:1447-51. [PubMed: 9772842]

10. Descatha A, Dale A-M, Franzblau A, Coomes G, Evanoff B. Diagnostic strategies using physical examination are minimally useful in defining carpal tunnel syndrome in population-based research studies. Occup Environ Med. 2010; 67:133-135. [PubMed: 19854697]

11. de Krom MC, Knipschild PG, Kester AD, Thijs C, Boekkooi PF, Spaaris F. Carpal tunnel syndrome: prevalence in the general population. J Clin Epidemiol. 1992; 45:373-376. [PubMed: 1569433]

12. Jaeschke R, Guyatt GH, Sackett DL. User's guide to the medial literature. III. How to use an article about a diagnostic test. B. What are the results and will they help me in caring for my patients? The evidence base working group. JAMA. 1994; 271:703-707. [PubMed: 8309035]

13. Ferry S, Pritchard T, Keenan J, Croft P, Silman A. Estimating the prevalence of delayed median nerve conduction in the general population. Br J Rheumatol. 1998; 37:630-635. [PubMed: 9667616]

14. Walker-Bone K, Palmer KT, Reading I, Coggon D, Cooper C. Prevalence and impact of musculoskeletal disorders of the upper limb in the general population. Arth Rheum. 2004; 51:642651. [PubMed: 15334439]

15. Ferry S, Silman A, Pritchard T, Keenan J, Croft P. The association between different patterns of hand symptoms and objective evidence of median nerve compression: A community-based survey. Arth Rheum. 1998; 41:720-724. [PubMed: 9550482]

16. Atroshi I, Gummesson C, Johnsson R, Ornstein E, Ranstam J, Rosen I. Prevalence of carpal tunnel syndrome in the general population. JAMA. 1999; 282:153-158. [PubMed: 10411196]

17. Stevens JC, Sun S, Beard CM, OFallon WM, Kurland LT. Carpal tunnel syndrome in Rochester, Minnesota, 1961 to 1980. Neurology. 1988; 38:134-138. [PubMed: 3336444]

18. Vessey MP, Villard Mackintosh L, Yeates D. Epidemiology of carpal tunnel syndrome in women of childbearing age. Findings in a large cohort study. Int J Epidemiol. 1990; 19:655-659.

[PubMed: 2262260] 
19. McCormick, A.; Fleming, D.; Charlton, J. Morbidity statistics from general practice. 4th National Study 1991-2. HMSO; London: 1992. Series MB5 No 3

20. McCormack RR Jr, Inman RD, Wells A, Berntsen C, Imbus HR. Prevalence of tendinitis and related disorders of the upper extremity in a manufacturing workforce. J Rheumatol. 1990; 17:958-964. [PubMed: 2213764]

21. Silverstein, BA. The prevalence of upper extremity cumulative disorders in industry (Thesis). The University of Michigan, Occupational Health and Safety; 1985.

22. Nordstrom DL, DeStefano F, Vierkant RA, Layde PM. Incidence of diagnosed carpal tunnel syndrome in a general population. Epidemiology. 1998; 9:342-345. [PubMed: 9583428]

23. Coggon D, Martyn C, Palmer KT, Evanoff B. Assessing case definitions in the absence of a diagnostic gold standard. Intl J Epidemiol. 2005; 34:949-952.

24. Barnhart S, Demers PA, Miller M, Longstreth WTJ, Rosenstock L. Carpal tunnel syndrome among ski manufacturing workers. Scand J Work, Environ Health. 1991; 17:46-52. [PubMed: 2047806]

25. Karhu O, Kansi P, Kuorinka I. Correcting working postures in industry: A practical method for analysis. Applied Ergonomics. 1977; 8.4:199-201. [PubMed: 15677243]

26. McAtamney L, Corlett EN. RULA: a survey method for the investigation of work-related upper limb disorders. Applied Ergonomics. 1993; 24:91-99. [PubMed: 15676903]

27. Palmer KT, Haward B, Griffin MJ, Bendall H, Coggon D. Validity of self-reported occupational exposures to hand-transmitted and whole-body vibration. Occup Environ Med. 2000; 57:237-241. [PubMed: 10810109]

28. Hagberg M, Morgenstern H, Kelsh M. Impact of occupations and job tasks on the prevalence of carpal tunnel syndrome. Scand J Work Environ Health. 1992; 18:337-345. [PubMed: 1485158]

29. National Institute for Occupational Health and Safety. Musculoskeletal Disorders and Workplace Factors. A Critical Review of Epidemiologic Evidence for Work-related Musculoskeletal Disorders of the Neck, Upper Extremity, and Low Back. US Department of Health and Human Sciences/NIOSH; Cincinnati, OH: 1997. Publication no. 97-141

30. Kuorinka, I.; Forcier, L., editors. Work-related Musculoskeletal Disorders (WMSDs): A Reference Book for Prevention. Taylor \& Francis; London: 1995.

31. Palmer KT, Harris EC, Coggon D. Carpal tunnel syndrome and its relation to occupation: A systematic literature review. Occup Med. 2007; 57:57-66.

32. Bovenzi M, Zadini A, Franzinelli A, Borgogni F. Occupational musculoskeletal disorders in the neck and upper limbs of forestry workers exposed to hand-arm vibration. Ergonomics. 1991; 34:547-562. [PubMed: 1653132]

33. Bovenzi M, Italian Study Group on Physical Hazards in the Stone Industry. Hand-arm vibration syndrome and dose-response relation for vibration induced white finger among quarry drillers and stonecarvers. Occup Environ Med. 1994; 51:603-611. [PubMed: 7951792]

34. Chatterjee DS, Barwick DD, Petrie A. Exploratory electromyography in the study of vibrationinduced white finger in rock drillers. Br J Ind Med. 1982; 39:89-97. [PubMed: 7066226]

35. Farkkila M, Pyykko I, Jantti V, Aatola S, Starck J, Korhonen O. Forestry workers exposed to vibration: a neurological study. Br J Ind Med. 1988; 45:188-192. [PubMed: 2831932]

36. Koskimies K, Farkkila M, Pyykko I, et al. Carpal tunnel syndrome in vibration disease. British Journal of Industrial Medicine. 1990; 47:411-416. [PubMed: 2378818]

37. Abbas MF, Faris RH, Harber PI, et al. Worksite and personal factors associated with carpal tunnel syndrome in an Egyptian electronics assembly factory. Int J Occup Environ Health. 2001; 7:3136. [PubMed: 11210010]

38. Bystrom S, Hall C, Welander T, Kilbom A. Clinical disorders and pressure-pain threshold of the forearm and hand among automobile assembly line workers. J Hand Surg - British Volume. 1995; 20:782-790.

39. Cannon LJ, Bernacki EJ, Walter SD. Personal and occupational factors associated with carpal tunnel syndrome. J Occup Med. 1981; 23:255-258. [PubMed: 7218063]

40. Leclerc A, Franchi P, Cristofari MF, et al. Study Group on Repetitive Work. Carpal tunnel syndrome and work organisation in repetitive work: a cross sectional study in France. Occup Environ Med. 1998; 55:180-187. [PubMed: 9624269] 
41. Leclerc A, Landre MF, Chastang JF, Niedhammer I, Roquelaure Y, Study Group on Repetitive Work. Upper-limb disorders in repetitive work. Scand J Work Environ Health. 2001; 27:268-278. [PubMed: 11560341]

42. Chiang HC, Chen SS, Yu HS, Ko YC. The occurrence of carpal tunnel syndrome in frozen food factory employees. Kao-Hsiung i Hsueh Ko Hsueh Tsa Chih [Kaohsiung Journal of Medical Sciences]. 1990; 6:73-80.

43. Kim JY, Kim JI, Son JE, Yun SK. Prevalence of carpal tunnel syndrome in meat and fish processing plants. J Occup Health. 2004; 46:230-234. [PubMed: 15215667]

44. Schottland JR, Kirschberg GJ, Fillingim R, Davis VP, Hogg F. Median nerve latencies in poultry processing workers: an approach to resolving the role of industrial "cumulative trauma" in the development of carpal tunnel syndrome. J Occup Med. 1991; 33:627-631. [PubMed: 1870015]

45. Morgenstern H, Kelsh M, Kraus J, Margolis W. A cross-sectional study of hand/wrist symptoms in female grocery checkers. Am J Ind Med. 1991; 20:209-218. [PubMed: 1951368]

46. Osorio AM, Ames RG, Jones J, et al. Carpal tunnel syndrome among grocery store workers. Am J Ind Med. 1994; 25:229-245. [PubMed: 8147395]

47. McCormack RR Jr, Inman RD, Wells A, Berntsen C, Imbus HR. Prevalence of tendinitis and related disorders of the upper extremity in a manufacturing workforce. J Rheumatol. 1990; 17:958-964. [PubMed: 2213764]

48. Punnett L, Robins JM, Wegman DH, Keyserling WM. Soft tissue disorders in the upper limbs of female garment workers. Scand J Work Environ Health. 1985; 11:417-425. [PubMed: 4095519]

49. Liss GM, Jesin E, Kusiak RA, White P. Musculoskeletal problems among Ontario dental hygienists. Am J Ind Med. 1995; 28:521-540. [PubMed: 8533793]

50. Rosecrance JC, Cook TM, Anton DC, Merlino LA. Carpal tunnel syndrome among apprentice construction workers. Am J Ind Med. 2002; 42:107-116. [PubMed: 12125086]

51. Andersen JH, Thomsen JF, Overgaard E, et al. Computer use and carpal tunnel syndrome: a 1-year follow-up study. JAMA. 2003; 289:2963-2969. [PubMed: 12799404]

52. Chiang HC, Ko YC, Chen SS, Yu HS, Wu TN, Chang PY. Prevalence of shoulder and upper-limb disorders among workers in the fish-processing industry. Scand J Work Environ Health. 1993; 19:126-131. [PubMed: 8316780]

53. de Krom MC, Kester AD, Knipschild PG, Spaans F. Risk factors for carpal tunnel syndrome. American Journal of Epidemiology. 1990; 132:1102-1110. [PubMed: 2260542]

54. Moore JS, Garg A. Upper extremity disorders in a pork processing plant: relationships between job risk factors and morbidity. Am Ind Hygiene Assn Journal. 1994; 55:703-715.

55. Nathan PA, Meadows KD, Doyle LS. Occupation as a risk factor for impaired sensory conduction of the median nerve at the carpal tunnel. J Hand Surgery - British Volume. 1988; 13:167-170.

56. Nathan PA, Keniston RC, Myers LD, Meadows KD. Longitudinal study of median nerve sensory conduction in industry: relationship to age, gender, hand dominance, occupational hand use, and clinical diagnosis. J Hand Surgery - American Volume. 1992; 17:850-857.

57. Nordstrom DL, Vierkant RA, Layde PM, Smith MJ. Comparison of self-reported and expertobserved physical activities at work in a general population. Am J Ind Med. 1998; 34:29-35. [PubMed: 9617385]

58. Roquelaure Y, Mechali S, Dano C, et al. Occupational and personal risk factors for carpal tunnel syndrome in industrial workers. Scand J Work Environ Health. 1997; 23:364-369. [PubMed: 9403467]

59. Tanaka S, Wild DK, Cameron LL, Freund E. Association of occupational and non-occupational risk factors with the prevalence of self-reported carpal tunnel syndrome in a national survey of the working population. Am J Ind Med. 1997; 32:550-556. [PubMed: 9327082]

60. Wieslander G, Norback D, Gothe CJ, Juhlin L. Carpal tunnel syndrome (CTS) and exposure to vibration, repetitive wrist movements, and heavy manual work: a case-referent study. Br J Ind Med. 1989; 46:43-47. [PubMed: 2920142]

61. Stevens JC, Witt JC, Smith BE, Weaver AL. The frequency of carpal tunnel syndrome in computer users at a medical facility. Neurology. 2001; 56:1568-1570. [PubMed: 11402117]

62. Viikari-Juntura E, Silverstein B. Role of physical load factors in carpal tunnel syndrome. Scandinavian Journal of Work Environment and Health. 1999; 25:163-185. 
63. Andersson A. Reaction in the tissues of the carpal tunnel after repeated contractions of the muscles innervated by the median nerve. Scandinavian Journal of Plastic Reconstructive Surgery Supplement. 1973; 9:1-67.

64. [accessed 23rd August 2010] Social Security (Industrial Injuries) (Prescribed Diseases) Regulations SI 1985/967, Regulations 2 \& 4, Schedule 1. http://www.iiac.org.uk/pdf/ dwp_d031890-edit.pdf - see entry for A12

65. Marshall SC, Tardif G, Ashworth NL. Local corticosteroid injection for carpal tunnel syndrome. Cochrane Database of Systematic Reviews. 2007; (2) Art. No: CD001554. DOI: 10.1002/14651858.CD001554.pub2.

66. O’Connor D, Marshall SC, Massy-Westropp N. Non-surgical treatment (other than steroid injection) for carpal tunnel syndrome. Cochrane Database of Systematic Reviews. 2003; (1) Art. No.: CD003219. DOI: 10.1002/14651858.CD003219.

67. Health and Safety Executive. Work-related upper limb disorders: a guide to prevention. HS(G)60. HMSO; London: 1990. 


\section{Box 1: Prevention by following good ergonomic principles [67]}

Physical risk factors in industry include: short cycle repetitive activities; static loading (e.g. standing, and carrying); awkward postures; undesirable load on muscles and torques on joints.

To avoid injury, ergonomic theory advocates

- minimising work effort by adopting 'good' postures, which allow strong muscles to contribute

- avoiding prolonged static loading (which interrupts the blood supply)

- minimising the forces that have to be applied (e.g. by improving tool design)

- ensuring the tool fits the worker (e.g. correct sized handle) and is fit for purpose

- avoiding application of forces at the extremes of joint movement

- avoiding repetition of the same movements- by mixing the pattern of work and slowing the cycle time

- allowing enough rest breaks

- avoiding forceful twisting or rotation of the wrist, movement of the wrist from side to side, highly flexed fingers and wrist, and upper limb motions beyond the range of comfort

- minimising adverse co-factors (e.g. reducing the vibration of tools by damping; improving lighting and layout) 


\section{Pointers for practice}

- CTS probably affects $0.6 \%-2 \%$ of working-aged people, depending on case definition

- Hand diagrams are an aid to clear and reproducible history taking

- Look for an 'extensive median' distribution of symptoms (extensively affecting the palmar surfaces of the medial three digits and not elsewhere) - this is a good marker of CTS

- Although the classical triad (median nerve distributions, physical signs and delayed nerve conduction) forms the basis of diagnosis, patients with only some of these features may benefit from treatment 


\section{Pointers for practice - Risk profiles}

- Reasonable evidence exists that regular, prolonged use of hand-held powered vibratory tools more than doubles the risk of CTS

- There is substantial evidence for similar or even higher risks from prolonged and highly repetitious flexion and extension of the wrist, especially when allied with a forceful grip.

- On the balance of evidence keyboard and computer use do not cause CTS. 


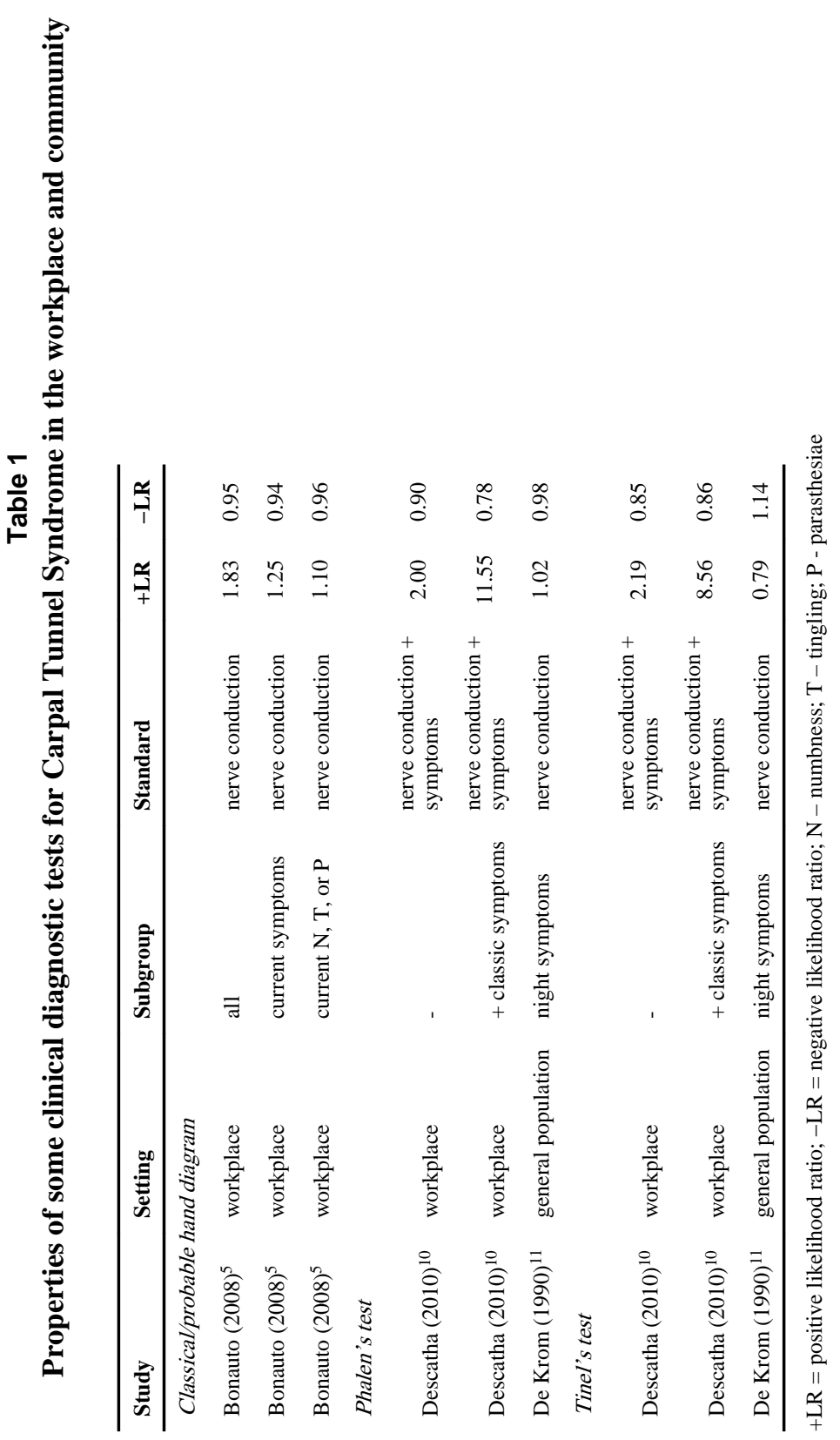

Best Pract Res Clin Rheumatol. Author manuscript; available in PMC 2011 July 28. 
Table 2

Frequency and interrelation of patterns of numbness and/or tingling in the right and left hands of 2,142 adults, aged 20-64 years, in the past 7 days (adapted from Reading et al [2] with permission of the publishers)

\begin{tabular}{lccc}
\hline & \multicolumn{3}{c}{$\%(\mathbf{N})$} \\
\cline { 2 - 4 } & Right hand & Left hand & Either/both hands \\
\hline Extensive median $^{a}$ & $0.7(16)$ & $0.8(18)$ & $1.2(25)$ \\
Limited median $^{b}$ & $1.4(31)$ & $1.3(27)$ & $2.2(47)$ \\
Non-median & $4.4(94)$ & $4.6(98)$ & $6.8(146)$ \\
All fingers & $6.0(128)$ & $6.1(131)$ & $7.8(167)$ \\
Mixed & $11.0(237)$ & $9.4(202)$ & $13.7(293)$ \\
\hline Total & $23.6(505)$ & $22.2(476)$ & $31.7(678)$ \\
\hline $\begin{array}{l}a \\
\text { confined to the palmar surfaces of } \geq 6 \text { phalanges from the medial three digits }\end{array}$ \\
$\begin{array}{l}\text { confined to the palmar surfaces of 1-5 phalanges from the medial three digits }\end{array}$
\end{tabular}


Table 3

Effect of case definition on the relation between Carpal Tunnel Syndrome and repetitive work (adapted from Barnhart et al [24])

\begin{tabular}{lccc}
\hline Criteria & $\begin{array}{c}\text { Repetitive } \\
(\boldsymbol{\%})\end{array}$ & $\begin{array}{c}\text { Non- } \\
\text { repetitive (\%) }\end{array}$ & RR \\
\hline Tingling & 85 & 70 & 1.2 \\
Nocturnal hand pain & 67 & 46 & 1.5 \\
One/more signs * & 45 & 21 & 2.2 \\
Nerve conduction only & 34 & 19 & 1.8 \\
Nerve conduction + signs * & 15 & 3 & 4.9 \\
\hline * & & & \\
Tinel's test or Phalen's test positive &
\end{tabular}


Table 4

Association of numbness and tingling in the hands with low vitality, neck pain and occupational activities (adapted from Reading et al [2] with permission of the publishers)

\begin{tabular}{|c|c|c|c|c|}
\hline \multirow[b]{2}{*}{$\begin{array}{l}\text { Pattern of numbness/tingling in past } 7 \\
\text { days }\end{array}$} & \multicolumn{4}{|c|}{ PR $(95 \% \mathrm{CI})$} \\
\hline & Low vitality & $\begin{array}{c}\text { Neck pain + } \\
\text { restricted } \\
\text { movement }\end{array}$ & $\begin{array}{c}\text { Repeated } \\
\text { finger/wrist } \\
\text { movements }>4 \\
\text { h/day }\end{array}$ & $\begin{array}{l}\text { Bending \& } \\
\text { straightening the } \\
\text { elbow for }>1 \mathrm{~h} / \mathrm{day}\end{array}$ \\
\hline Extensive median in one/both hands & $0.8(0.3$ to 3.1$)$ & $1.4(0.2$ to 9.5$)$ & $2.6(1.0$ to 6.8$)$ & $3.1(1.0$ to 9.5$)$ \\
\hline Limited median in one/both hands & $1.2(0.6$ to 2.7$)$ & $3.7(1.5$ to 8.9$)$ & $1.2(0.6$ to 2.4$)$ & $1.1(0.6$ to 2.3$)$ \\
\hline Non-median in one/both hands & $1.9(1.3$ to 2.8$)$ & $3.2(1.8$ to 5.7$)$ & $1.4(0.9$ to 2.1$)$ & $1.3(0.9$ to 2.0$)$ \\
\hline All fingers, both hands & $2.5(1.4$ to 4.3$)$ & $4.9(2.8$ to 8.6$)$ & $1.4(0.8$ to 2.2$)$ & $1.3(0.8$ to 2.1$)$ \\
\hline All fingers, one hand & $1.6(0.8$ to 2.9$)$ & $2.8(1.2$ to 6.8$)$ & $1.1(0.6$ to 2.0$)$ & $1.1(0.89$ to 2.5$)$ \\
\hline No symptoms, either hand & 1 & 1 & 1 & 1 \\
\hline
\end{tabular}




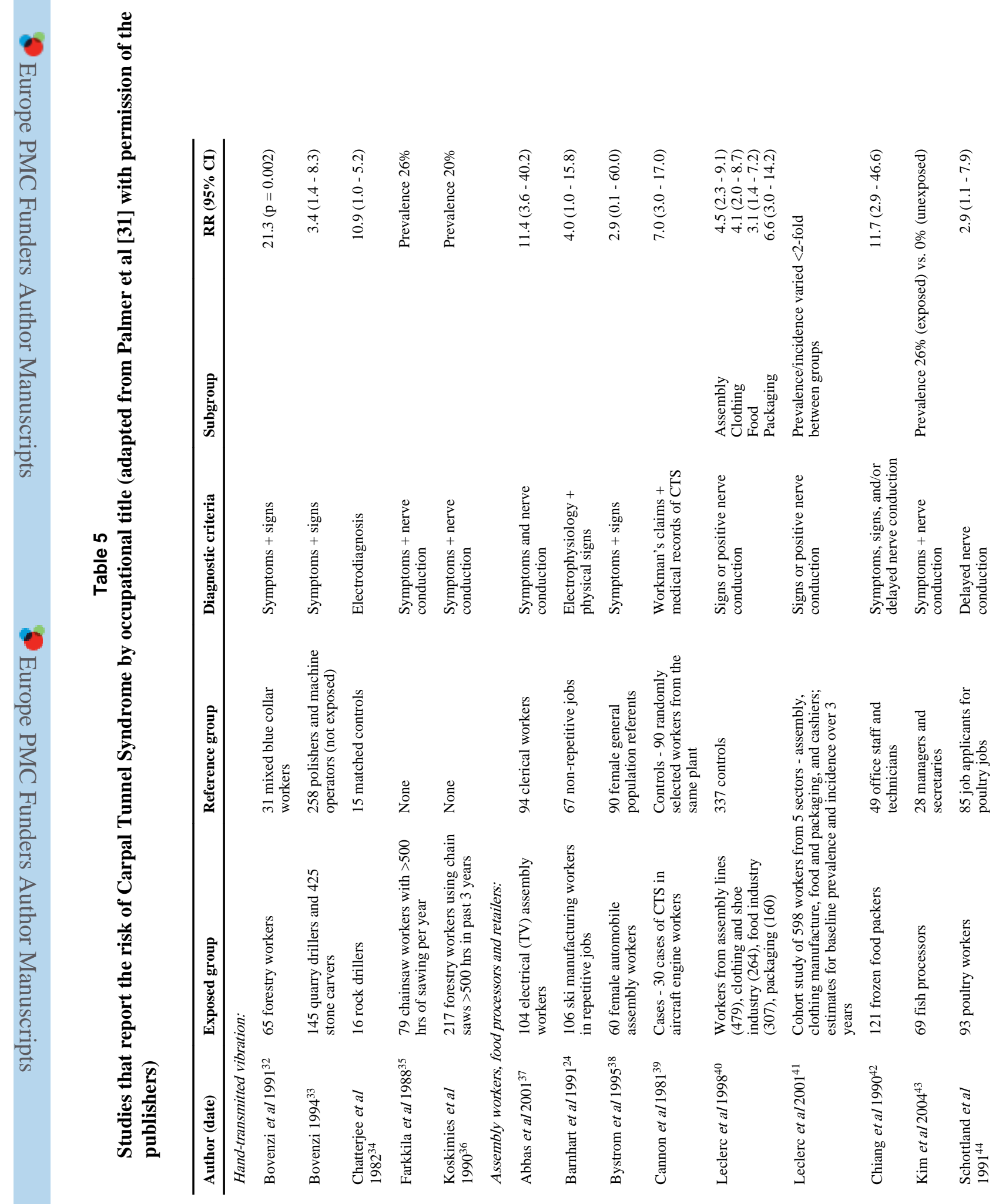




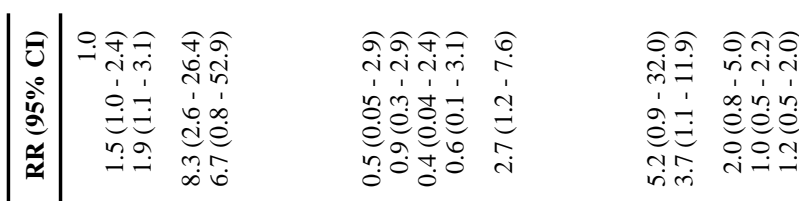

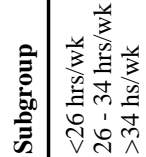

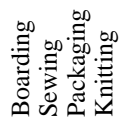

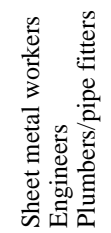

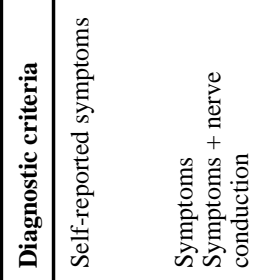

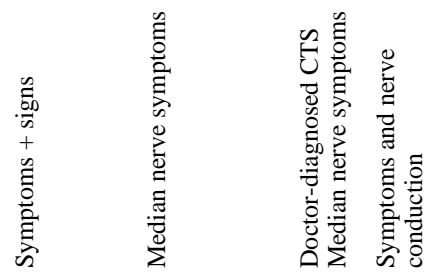

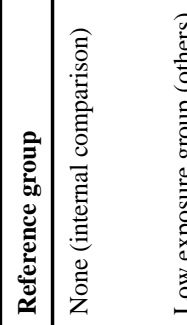

\begin{tabular}{l}
0 \\
0 \\
0 \\
0 \\
0 \\
2 \\
\hline \\
0 \\
0 \\
0 \\
0 \\
0 \\
0 \\
0 \\
0 \\
0 \\
0 \\
0 \\
0
\end{tabular}

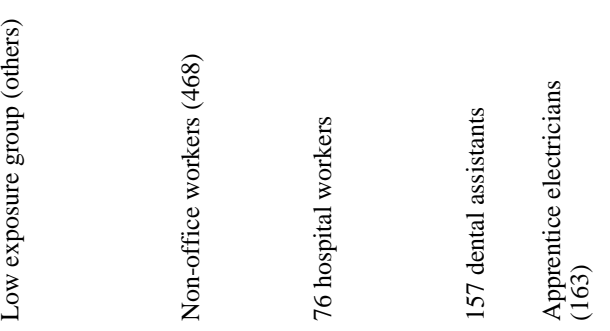

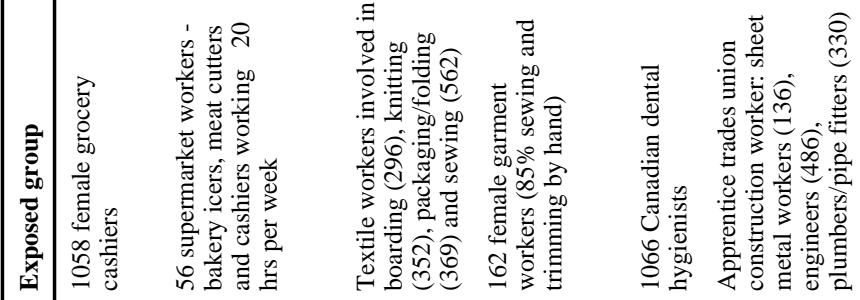

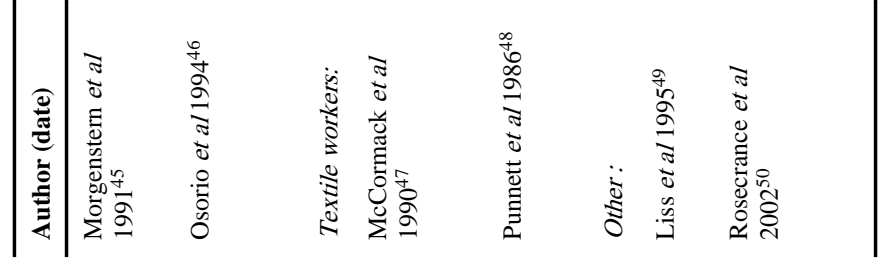




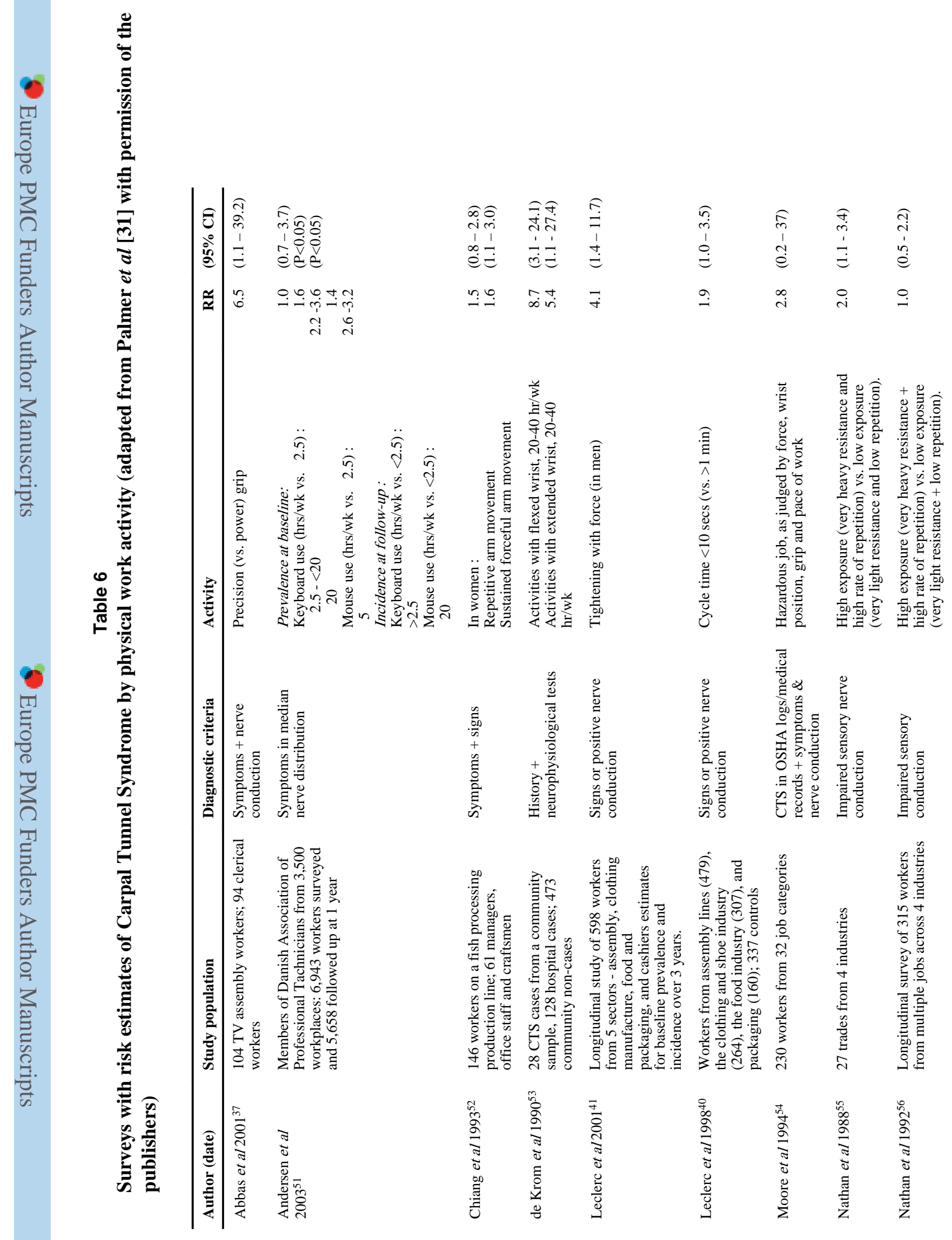




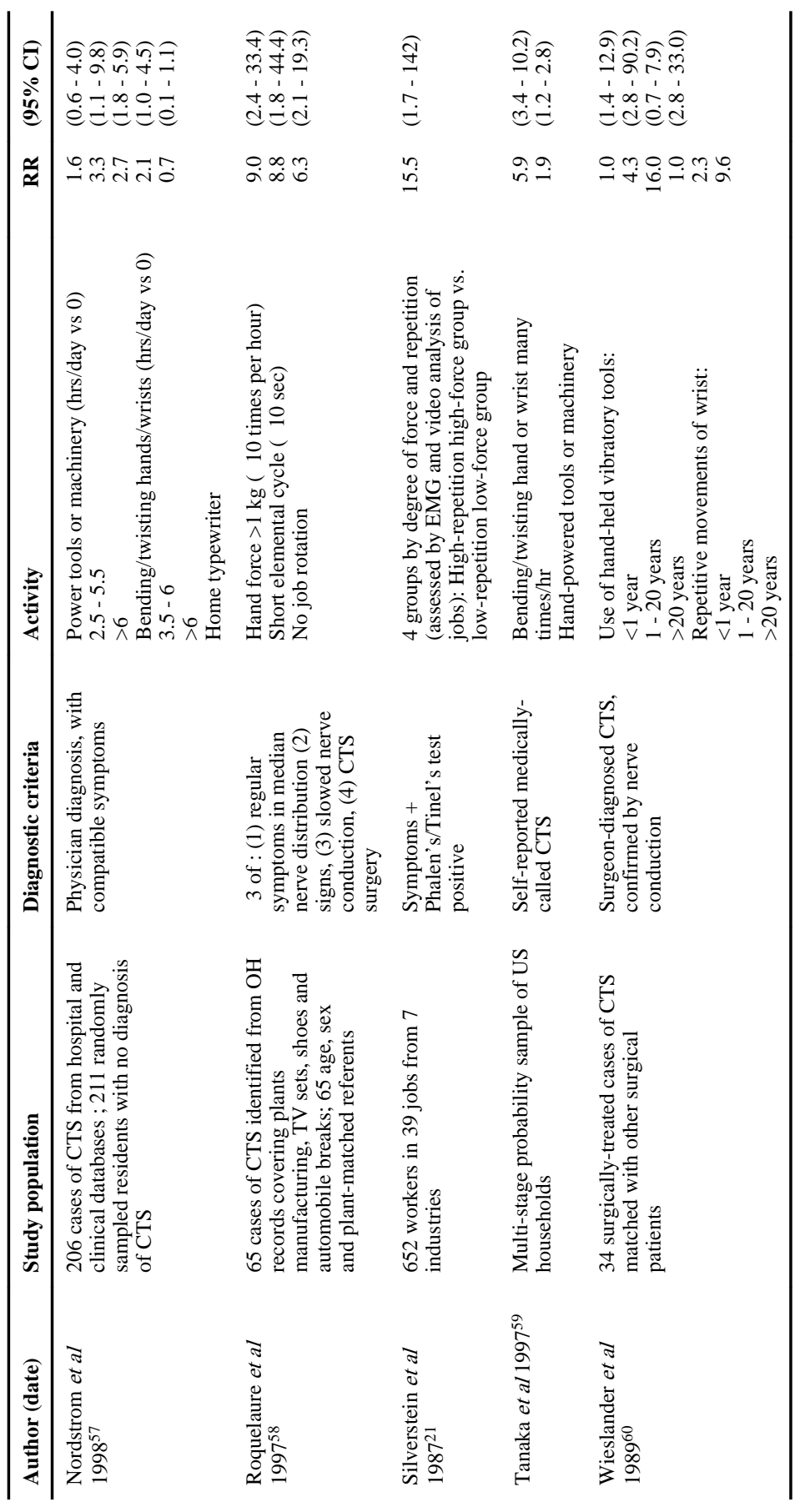

